\title{
Early Diagnosis of Thrombotic Microangiopathy by Paraffin Sections of Aspirated Bone-marrow
}

\author{
T. E. BLECHER and A. B. RAPER \\ From the Department of Pathology (Haematology), United Bristol Hospitals
}

Thrombotic microangiopathy, particularly the type affecting adults and usually known as thrombotic thrombocytopenic purpura, has until recently been regarded as an almost invariably fatal disease. In infancy and early childhood it is generally described as the haemolytic-uraemic syndrome. However, the latter syndrome may result from more than one pathological process, and certainly it is unknown what proportion of children with haemolysis and uraemia have microangiopathic lesions; but about half of these patients survive with modern treatment (Gianantonio, Vitacco, Mendilaharzu, Rutty, and Mendilaharzu, 1964; Shinton, Galpine, Kendall, and Williams, 1964; McQuiggan, Oliver, Littler, and Cerny, 1965; McLean, Jones, and Sutherland, 1966). By contrast, the number of adult patients with thrombotic microangiopathy who have recovered has been small; Amorosi and Ultmann (1966) in an exhaustive review of 271 reported cases found only 13 survivors of 'classic TTP' (thrombotic thrombocytopenic purpura).

Allanby, Huntsman, and Sacker (1966) have recently reported a further case of thrombotic microangiopathy in an adult, treated and apparently cured by the use of a magnesium-heparin-corticosteroid régime, and we have recently been impressed by the rapid and apparently complete recovery (Case 2 below) of a boy of 15 with this disease, who was treated by the same method in Bristol. It is probable that the very prompt institution of this treatment played a part in the successful outcome, and it seems that a definitive diagnosis of thrombotic microangiopathy at the earliest possible moment in suspected cases has become a matter of considerable importance.

Thrombotic microangiopathy is not a common disease, and early diagnosis depends upon recognizing a combination of haemolytic anaemia, purpura, renal impairment, neurological disturbances, and frequently of fever; but to make the diagnosis with

Received July 14, 1966. certainty it is necessary to demonstrate the histological lesion. Of the various methods (reviewed below) that have been advocated for securing biopsy material for the histological diagnosis, the simplest appears to be the preparation of paraffin sections from marrow obtained by needle aspiration, and this method is probably the safest in the presence of thrombocytopenia, which is common in these cases. We report here the success of this method in two patients with thrombotic microangiopathy seen in this department in the past six years.

\section{Case Reports}

Case 1. An infant was admitted on February 7, 1961, under the care of Professor A. V. Neale at the age of 7 months, one week after his first inoculation with poliovirus vaccine. He had had four days of increasing listlessness, drowsiness, and vomiting, and had passed dark urine. On examination, purpura, jaundice, and hepatomegaly were noted, but there was no evidence of respiratory or meningeal infection. The haemoglobin level was $4 \cdot 2 \mathrm{~g} . / 100 \mathrm{ml}$., total white count $17,800 / \mathrm{c} . \mathrm{mm}$., and platelet count $42,000 / \mathrm{c} . \mathrm{mm}$. The blood film showed extreme poikilocytosis, with fragmented, helmet, and burr cells, and occasional microspherocytes. There were numerous normoblasts, and a marked 'shift to the left' of the neutrophil series. The reticulocyte count was $15 \%$, the Schumm test was strongly positive, and the serum bilirubin reached $4 \mathrm{mg} . / 100 \mathrm{ml}$. The Coombs test was negative, and platelet antibodies could not be detected (Dr. R. G. Mitchell). Blood urea nitrogen was $66 \mathrm{mg} . / 100 \mathrm{ml}$. Albuminuria and cylindruria occurred for about two weeks.

A sample of tibial marrow was aspirated four days after admission. With the intention of dislodging actual vascular material, the suction applied was sudden and forcible. The smears showed normoblastic hyperplasia and numerous megakaryocytes, but these showed no platelet formation. About $0.25 \mathrm{ml}$. of the aspirate was placed in $2 \mathrm{ml} .10 \%$ bovine albumin with EDTA, and subsequently fixed in Zenker's formalin fixative, embedded in paraffin, sectioned, and stained with haematoxylin and eosin. Microscopically these sections showed occasional small vessels, mainly capillaries, with their 


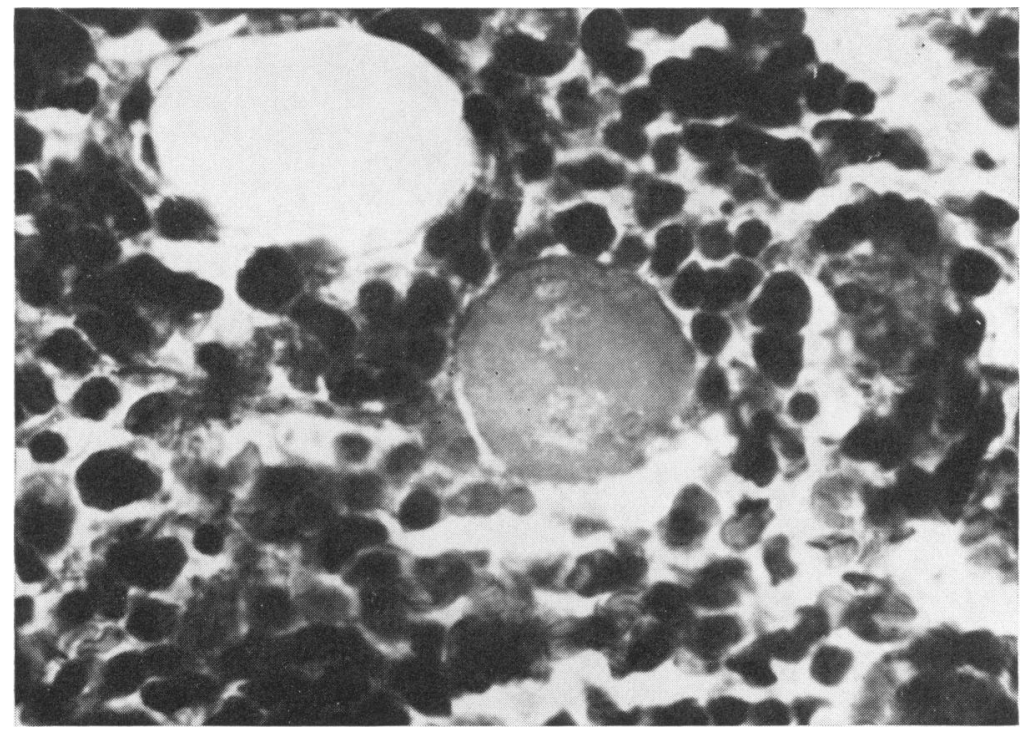

FIG. 1.-Case 1, aspirated bone-marrow. $(\times 400$.

lumina distended to a roughly circular cross-section by hyaline to slightly granular eosinophilic material. On occasions this material appeared to merge with the cytoplasm of the lining endothelial cells, but no endothelial proliferation or perivascular cellular reaction was found (Fig. 1).

A diagnosis of haemolytic-uraemic syndrome was made, and following blood transfusion (packed cells), hydrocortisone therapy, and penicillin and streptomycin injections, the child showed rapid clinical improvement and a gradual return to normal of all the haematological and biochemical abnormalities. Five years later his mother reports him to be very well.

Case 2. A 15-year-old boy was admitted in January 1966 under the care of Dr. D. H. Davies with a history of feeling unwell for three days, vomiting, mild headache, and the passage of red urine. He was pale and listless but afebrile, and the only abnormal physical sign was slight palatal purpura. The haemoglobin was $11.6 \mathrm{~g}$./ $100 \mathrm{ml}$. on admission, and had dropped to $9.0 \mathrm{~g} . / 100 \mathrm{ml}$. three days later. The blood film showed the same bizarre red cell abnormalities as in Case 1, but there was no normoblastaemia and the reticulocyte count was only $0.3 \%$; platelet count $7000 / \mathrm{c} . \mathrm{mm}$. and total white cell count $7000 /$ c.mm. The serum contained free haemoglobin, as did the urine, and gave a positive Schumm test. The Coombs test was negative, and platelet antibodies were not detectable (Dr. N. F. N. Brueton). The serum bilirubin reached $2 \cdot 1 \mathrm{mg}$. $/ 100 \mathrm{ml}$. and the reticulocyte count rose to $3 \cdot 1 \%$ by the 13 th day after admission. There was marked albuminuria and cylindruria, and the blood urea rose to $185 \mathrm{mg} . / 100 \mathrm{ml}$.

Smears of iliac crest marrow aspirated on the day after admission showed no erythroid hyperplasia, and in fact appeared normal in all respects except for the virtually complete absence of platelet-budding on the megakaryocytes. About $0.25 \mathrm{ml}$. of the aspirate was fixed in $3 \mathrm{ml}$. formalin-glacial acetic acid, paraffin-embedded, sectioned, and stained with haematoxylin and eosin. Examination of these sections showed only very occasional thrombotic lesions similar in all respects to those described in Case 1. Both the longitudinally and transversely sectioned eosinophilic plugs in capillaries (shown respectively in Fig. 2 and 3) were found in the same section, while other sections showed a few more plugged capillaries. An inguinal lymph node and a small biopsy of skin were taken four days after admittance to hospital, by which time the platelet count had risen to $98,000 /$ c.mm. These were both reported upon as not showing the lesions of thrombotic microangiopathy (Dr. A. C. Hunt).

Details of the treatment and recovery of this patient will be described separately.

\section{Discussion}

Necropsy studies have shown that the vascular lesions of thrombotic microangiopathy may occur in almost any organ of the body, notably in the small vessels of the capsular zone of the adrenal cortex, the myocardium, brain, liver, spleen, kidneys, pancreas, bone-marrow, and lymph nodes (Orbison, 1952; Singer, 1954). It is significant that Leavitt (quoted by Ruffolo, Pease, and Cooper, 1962), in an extensive study, consistently found lesions in the marrow, and very frequently in the lymph nodes.

Since Bernheim (1943) first suggested that this condition might be histologically diagnosable during life, the results of biopsy of several tissues have been reported. Muscle obtained both by biopsy and at 


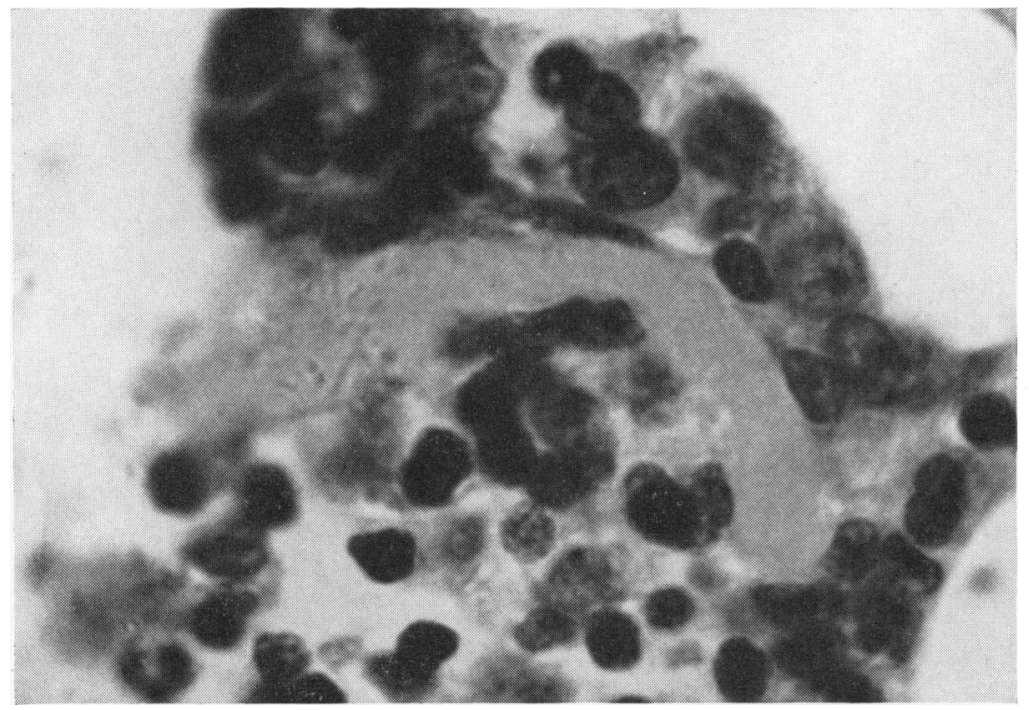

FIG. 2.-Case 2, aspirated bone-marrow. $(\times 600$.

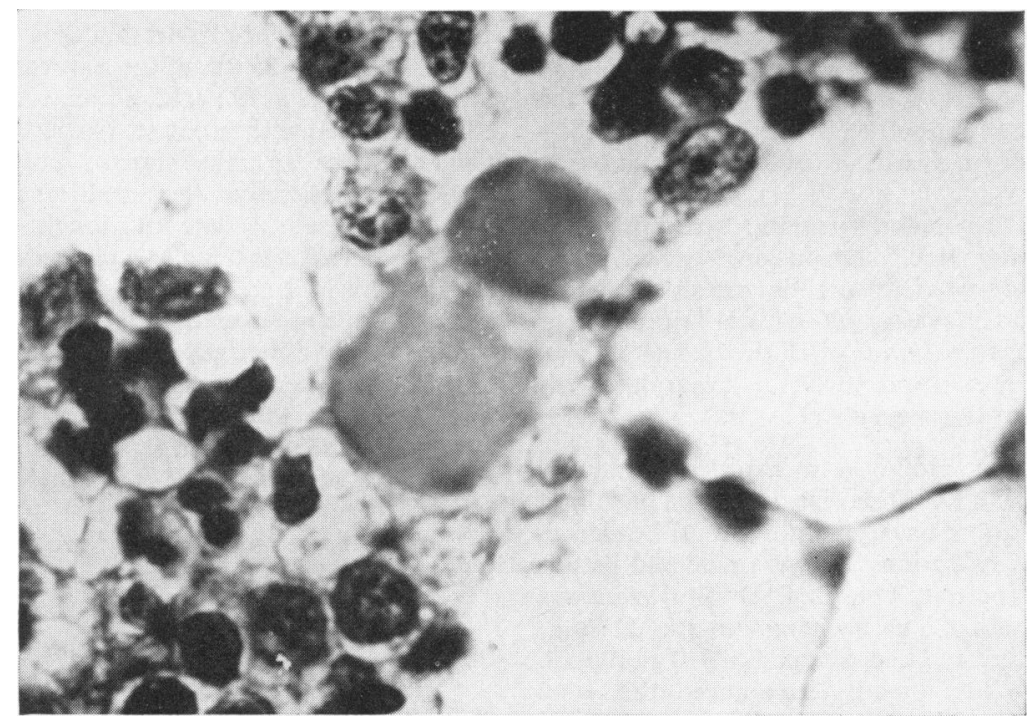

FIG. 3.-Case 2, aspirated bone-marrow. ( $\times$ 700.)

necropsy has usually been devoid of the specific lesions, as in 13 cases mentioned by Symmers (1956), though it gave a positive result in one of Symmers's own cases, and in one of Burke and Hartmann's (1959) two cases. In the other two fatal cases of thrombotic microangiopathy reported by Symmers the characteristic histological changes were present in the uterine curettings and appendix, respectively, which had been obtained surgically before the disease had developed or the diagnosis had been suspected. In a number of cases splenectomy has been performed as a therapeutic measure, and most spleens have shown the diagnostic lesion (reviewed by Symmers, 1956). Skin biopsies have usually been negative, as in cases reported by Adelson and Stefanini (1952), Morey, White, and Daily (1956), Stuart and MacGregor-Robertson (1956), Burke and Hartmann (1959), and Griffiths and Irving (1961); though positive results were obtained in the case reported by Beigelman (1951) 
and in one of the five cases mentioned by Symmers (1956).

Lymph node biopsy, on the other hand, has often revealed the thrombotic lesions (Adelson and Stefanini, 1952; Morey et al., 1956; Symmers, 1956; Sharnoff, 1957; Robinson, Orchard, and Eden, 1958; Brown and Taylor, 1963; Casale, 1965), and Alcorn and Fadell (1961) reported the invariable presence of abundant characteristic lesions in necropsy specimens of lymph nodes from five cases of the disease. The lesions were absent even at necropsy from lymph nodes in one of Symmers's (1956) cases and in 1 of the 7 cases of Ruffolo et al. (1962).

The suggestion that bone-marrow biopsy might demonstrate the lesions of thrombotic microangiopathy came from necropsy studies. Fitzgerald, Auerbach, and Frame (1947) had found lesions in the marrow of their three patients at necropsy, and suggested that these might be found during life; and Symmers (1956) stated that, a 'high proportion of marrows examined post mortem in cases of thrombotic microangiopathy has shown the characteristic lesions; bone marrow is probably second only to liver among tissues accessible to biopsy which are likely to contain diagnostic lesions'. Meantime at the Mayo Clinic (Cooper, Stickney, Pease, and Bennett, 1952; Ruffolo et al., 1962) diagnostic lesions had been found in marrow aspirates from six out of eight patients, all eight of whom were later shown at necropsy to have lesions in this site. Successful diagnosis by marrow aspiration was also achieved in one patient by Wile and Sturgeon (1956), and by marrow trephine in the case reported by Morey et al. (1956). On the other hand, sections of aspirated or trephined bone marrow failed to show the thrombotic lesions in single cases reported by Singer, Motulsky, and Shanberge (1950), Green and Green (1953), Burke and Hartmann (1959), and in the case reported by Ritz, Groisser, and Banowitch (1956) in which, nevertheless, the lesions were found in the marrow sections at necropsy.

Histological diagnosis during life has thus been most successful when biopsies have been taken from lymph nodes or bone-marrow. As a practical measure we consider the bone-marrow to be the first site of choice. This is partly because suitable nodes may not be available for biopsy, since superficial lymph node enlargement is an inconstant finding in thrombotic thrombocytopenic purpura (Wile and Sturgeon, 1956), and partly because the technique of needle aspiration from bone-marrow is safe, and is also relatively simple to arrange as a bedside procedure, compared with biopsy of other tissues. Moreover, as Ruffolo and his colleagues point out, samples from multiple sites can readily be obtained if necessary.

These advantages have special relevance to paediatric practice, and if exploited could well lead to a further appraisal of the role of microangiopathy in the haemolytic-uraemic syndrome in children. This is important because the full justification for the use of anticoagulants in such cases is the demonstration of thrombotic lesions in small vessels. We recommend aspiration of the marrow for histological section as the first step to be taken as soon as clinical suspicion of a thrombotic microangiopathy is aroused, e.g. by the association of two or more of the following features: thrombocytopenia, haemolytic anaemia especially with bizarre schistocytes, acute renal disease, transient neurological disturbances. If this method should fail to give a positive result, it appears from the published reports that lymph node biopsy would then be a suitable additional step to take. Very early diagnosis, possibly even by frozen section, might enable early institution of the encouraging new methods of treatment to improve greatly the previously gloomy outlook in this group of diseases.

\section{Summary}

Early histological diagnosis of thrombotic microangiopathy is important because improved methods of treatment are now available.

The published reports indicate that biopsy of lymph nodes or of bone-marrow is most likely to provide histological confirmation of the diagnosis.

We report the finding of the characteristic microangiopathic lesions in paraffin sections of aspirated marrow in two patients, aged 7 months and 15 years, respectively. This procedure is safe, simple, and especially applicable to children; it is recommended as a necessary step as soon as clinical suspicion of a thrombotic microangiopathy (including the haemolytic-uraemic syndrome) is aroused.

\section{REFERENCES}

Adelson, E., and Stefanini, M. (1952). Studies on platelets. VI. Demonstration and characterization of a heterologous (Forssman) platelet agglutinin. Blood, 7, 700.

Alcorn, M. O., Jr., and Fadell, E. J. (1961). A note on the antemortem histologic diagnosis of thrombotic thrombocytopenic purpura. Amer. F. clin. Path., 35, 546.

Allanby, K. D., Huntsman, R. G., and Sacker, L. S. (1966). Thrombotic microangiopathy. Lancet, 1, 237.

Amorosi, E. L., and Ultmann, J. E. (1966). Thrombotic thrombocytopenic purpura. Report of 16 cases and review of the literature. Medicine (Baltimore), 45, 139.

Beigelman, P. M. (1951). Variants of the platelet thrombosis syndrome and their relationship to disseminated lupus. Arch. Path., 51, 213.

Bernheim, A. I. (1943). Widespread capillary and arteriolar platelet thrombi. F. Mt Sinai Hosp., 10, 287.

Brown, J., and Taylor, R. F. (1963). Thrombotic thrombocytopenic: purpura. Canad. med. Ass. F., 89, 613. 
Burke, H. A., Jr., and Hartmann, R. C. (1959). Thrombotic thrombocytopenic purpura. Arch. intern. Med., 103, 105.

Casale, L. A. (1965). Thrombotic thrombocytopenic purpura: report of a case and review of 157 cases. Hawaii med.f., 25, 93

Cooper, T., Stickney, J. M., Pease, G. L., and Bennett, W. A. (1952) Thrombotic thrombocytopenic purpura: confirmation of clinical diagnosis by bone marrow aspiration. Amer. F. Med., 13, 374.

Fitzgerald, P. J., Auerbach, O., and Frame, E. (1947). Thrombocytic acroangiothrombosis (platelet thrombosis of the capillaries, arterioles, and venules). Blood, $2,519$.

Gianantonio, C., Vitacco, M., Mendilaharzu, F., Rutty, A., and Mendilaharzu, J. (1964). The hemolytic-uremic syndrome. f. Pediat., 64, 478.

Green, W. S., Jr., and Green, T. W. (1953). Thrombotic thrombocytopenic purpura. Ann. intern. Med., 39, 371.

Griffiths, J., and Irving, K. G. (1961). A haemolytic-uraemic syndrome in infancy. Arch. Dis. Childh., 36, 500.

McLean, M. M., Jones, C. H., and Sutherland, D. A. (1966). Haemolytic-uraemic syndrome. A report of an outbreak. ibid., 41, 76.

McQuiggan, M. C., Oliver, W. J., Littler, E. R., and Cerny, J. C. (1965). The hemolytic uremic syndrome. f. Amer. med. Ass., 191, 787.

Morey, D. A. J., White, J. B., and Daily, W. M. (1956). Thrombotic thrombocytopenic purpura diagnosed by random lymph node biopsy. Arch. intern. Med., 98, 821.

Orbison, J. L. (1952). Morphology of thrombotic thrombocytopenic purpura with demonstration of aneurysms. Amer. F. Path., 28, 129.

Ritz, N. D., Groisser, V. W., and Banowitch, M. M. (1956). Thrombotic thrombocytopenic purpura with a positive Coombs' reaction. Amer. F. Med., 21, 468.

Robinson, M. J., Orchard, N. P., and Eden, A. R. (1958). Thrombotic microangiopathic haemolytic anaemia. Arch. Dis. Childh., 33, 520.

Ruffolo, E. H., Pease, G. L., and Cooper, T. (1962). Thrombotic thrombocytopenic purpura. Antemortem diagnosis. Arch. intern. Med., 110, 78.

Sharnoff, J. G. (1957). Thrombotic thrombocytopenic purpura. A report of three cases. Amer. F. Med., 23, 740.

Shinton, N. K., Galpine, J. F., Kendall, A. C., and Williams, H. P. (1964). Haemolytic anaemia with acute renal disease. Arch. Dis. Childh., 39, 455.

Singer, K. (1954). Thrombotic thrombocytopenic purpura Advanc. intern. Med., 6, 195.

—, Motulsky, A. G., and Shanberge, J. N. (1950). Thrombotic thrombocytopenic purpura. II. Studies on the hemolytic syndrome in this disease. Blood, 5, 434.

Stuart, A. E., and MacGregor-Robertson, G. (1956). Thrombotic thrombocytopenic purpura. A hyperergic micro-angiopathy. Lancet, 1, 475.

Symmers, W. St. C. (1956). Thrombotic microangiopathy. Histological diagnosis during life. ibid., 1, 592.

Wile, S. A., and Sturgeon, P. (1956). Thrombotic thrombocytopenic purpura. Review of the subject with a report of three cases in children. Pediatrics, 17, 882. 